\title{
Choledochal Malformation in Children: Lessons Learned from a Dutch National Study
}

\author{
Nederlandse Studiegroep voor Choledochus Cysten/malformaties (NeSCHoC) • \\ Maria. H. A. van den Eijnden ${ }^{1}$ - Ruben H. J. de Kleine ${ }^{2}$ - Ivo de Blaauw ${ }^{3}$. \\ Paul G. J. M. Peeters ${ }^{2}$ - Bart P. G. Koot ${ }^{4}$ Matthijs W. N. Oomen ${ }^{4}$. \\ Cornelius E. J. Sloots ${ }^{5}$ W. G. van Gemert ${ }^{6}$ - David C. van der Zee $^{7}$. \\ L. W. E. van Heurn ${ }^{4} \cdot$ Henkjan J. Verkade $^{1} \cdot$ Jim C. H. Wilde $^{8} \cdot$ Jan B. F. Hulscher $^{1}$
}

Published online: 6 June 2017

(c) The Author(s) 2017. This article is published with open access at Springerlink.com

\begin{abstract}
Introduction A choledochal malformation $(\mathrm{CM})$ is a rare entity, especially in the Western world. We aimed to determine the incidence of $\mathrm{CM}$ in the Netherlands and the outcome of surgery for CM in childhood.

Methods All pediatric patients who underwent a surgical procedure for type I-IV CM between 1989 and 2014 were entered into the Netherlands Study group on choledochal cyst/malformation. Patients with type V CM were excluded from the present analysis. Symptoms, surgical details, short-term ( $<30$ days) and long-term ( $>30$ days) complications were studied retrospectively.

Results Between January 1989 and December 2014, 91 pediatric patients underwent surgery for CM at a median age of 2.1 years (0.0-17.7 years). All patients underwent resection of the extrahepatic biliary tree with restoration of the continuity via Roux-en-Y hepaticojejunostomy. Twelve patients (12\%) were operated laparoscopically. Short-term complications, mainly biliary leakage and cholangitis, occurred in 20 patients $(22 \%)$, without significant correlations with weight or age at surgery or surgical approach. Long-term postoperative complications were mainly cholangitis $(13 \%)$ and anastomotic stricture (4\%). Eight patients (9\%) required radiological intervention or additional surgery. Surgery before 1 year of age (OR 9.3) and laparoscopic surgery (OR 4.4) were associated with more postoperative long-term complications. We did not observe biliary malignancies during treatment or follow-up.

Conclusion Surgery for CM carries a significant short- and long-term morbidity. Given the low incidence, we would suggest that (laparoscopic) hepatobiliary surgery for CM should be performed in specialized pediatric surgical centers with a wide experience in laparoscopy and hepatobiliary surgery.
\end{abstract}

Maria. H. A. van den Eijnden and Ruben H. J. de Kleine contributed equally to this study.

Jan B. F. Hulscher

j.b.f.hulscher@umcg.nl

1 Department of Pediatric Surgery, University of Groningen, University Medical Center Groningen, Hanzeplein 1, HPC BA20 Postbus 30.001, 9700RB Groningen, The Netherlands

2 Department of Hepato-Pancreatico-Biliary Surgery and Liver Transplantation, University of Groningen, University Medical Center Groningen, Hanzeplein 1, 9700RB Groningen, The Netherlands
3 Surgery-Division of Pediatric Surgery, Amalia Children's Hospital, Radboud University Nijmegen, Medical Center, Geert Grooteplein 10, 6525GA Nijmegen, The Netherlands

4 Department of Pediatric Surgery, Emma Children's Hospital, Academic Medical Center, University of Amsterdam, Meibergdreef 9, 1105AZ Amsterdam, The Netherlands

5 Department of Pediatric Surgery, Sophia Children's Hospital, Rotterdam, Erasmus Medical Center, Erasmas University, 'sGravendijkwal 230, 3015CE Rotterdam, The Netherlands 


\section{Introduction}

A choledochal malformation $(\mathrm{CM})$ is a rare biliary entity with an estimated incidence of 1:100-150,000 live births in Western countries $[1,2]$. In the Asian population, the incidence can be as high as 1:1000 live births. The reason for this Asian preponderance is still unknown [3]. CM is primarily a childhood disease: Up to $80 \%$ of patients are diagnosed before 10 years of age [4-6].

Mainstay of treatment is resection of the affected (extrahepatic) bile ducts with subsequent restoration of the continuity between biliary tract and intestines $[4,5,7,8]$. This complex surgery is associated with significant shortand long-term morbidity [8-10]. Timing of surgery, especially in asymptomatic infants, is difficult. Early surgery might prevent CM-related symptoms, while later surgery might diminish surgery-related complications [11-13]. In the Netherlands, most resections for $\mathrm{CM}$ are performed via a laparotomy [14]. However, the laparoscopic approach is gaining popularity [14-17].

Most reports on $\mathrm{CM}$ are case series from a single institution. In the present study, we describe results from over 25 years of experience with $\mathrm{CM}$ in the Netherlands. To this end, we collected data from the six Dutch pediatric surgical centers. We identified short- and long-term postoperative complications and searched for possible risk factors associated with worse postoperative outcomes. This way we aimed to identify possible targets for improvement of care. Our main focus was on differences in outcomes between early surgery versus delayed surgery and the differences between laparoscopic and open resection.

\section{Patients and methods}

We included all Dutch pediatric patients who were operated for $\mathrm{CM}<18$ years of age in the Netherlands between January 1, 1989 and December 31, 2014. Patients who were diagnosed with a type V CM were excluded. Data were collected from all academic pediatric surgical centers performing surgery for $\mathrm{CM}$, resulting in a national registry:

6 Department of Pediatric Surgery, University Medical Center Maastricht, University of Maastricht, P. Debyelaan 25, 6229HX Maastricht, The Netherlands

7 Department of Pediatric Surgery, University Medical Center Utrecht, University of Utrecht, Heidelberglaan 100, 3584CX Utrecht, The Netherlands

8 University Center of Pediatric Surgery of Western Switzerland, Division of Pediatric Surgery, University Hospitals of Geneva, Rue Gabrielle-Perret-Gentil 4, Geneva 1205, Switzerland
"Nederlandse Studiegroep voor CHoledochus Cysten/malformaties (NeSCHoC)."

Patient charts were reviewed retrospectively. The primary investigator (ME) collected data concerning patient demographics, age at diagnosis, type of $\mathrm{CM}$ according to Todani [18], age at surgical intervention, type of surgical intervention, surgical data and postoperative complications. Postoperative complications were defined as shortterm ( $<30$ days) and long-term ( $>30$ days) complications following the Clavien-Dindo classification [19]. Postoperative complications were defined as follows: cholangitis as fever (>38.5) with abdominal pain and jaundice, pancreatitis as abdominal pain with elevated serum amylase, wound infection as red discoloration of the surgical and/or drain wound, bile leakage as abdominal complaints and proven bilirubin in the abdominal fluid, intra-abdominal infections as fever and a proven bacterial infection confirmed via culture, ileus as $>1$ day of abdominal distension, vomiting and the absence of defecation and gas, liver(bile)stones as intrahepatic bile stones confirmed by ultrasonography, liver abscesses as circumscribed infection in the liver confirmed by ultrasonography and liver fibrosis/cirrhosis as confirmed histologically via liver biopsy.

We also collected the occurrence of biliary malignancies and survival data. We compared the outcomes after laparoscopic resection with the outcomes after resection via laparotomy, and the outcomes after surgery before 1 year of age with outcomes after surgery after 1 year of age. Follow-up was performed using the hospital databases. As surgical treatment of CM is only performed in a pediatric surgical center, all postoperative complications were collected from the patients' electronic or paper files in the pediatric surgical center where the resection was performed. Follow-up analysis was conducted from January 1, 1989 until of October 1, 2015. The study protocol was approved by the University Medical Center Groningen Ethics Committee (METC2015/115).

\section{Statistical analysis}

Differences between groups were tested with the $t$ test, Mann-Whitney $U$ and Wilcoxon signed rank test as appropriate. To determine statistical differences between ordinal values, the Chi-square or Fishers' exact test was used as appropriate, and odds ratio were calculated. Potential prognostic factors for overall postoperative complication-free survival were evaluated using univariate analysis. We used the log-rank test to compare groups for postoperative complication-free survival after surgery. $p$ values $<0.05$ were considered statistically significant. The SPSS IBM 22 package (Armonk, New York, United States) was used for statistical analysis. 


\section{Results}

We identified 91 patients $<18$ years who underwent surgical intervention for CM type I-IV in the Netherlands between January 1, 1989 and December 31, 2014. Based on this data the Dutch specimen-proven incidence of I-IV CM in patients $<18$ years is at least 1:59.000 live births [20].

\section{Patient cohort}

Median age at the start of CM-related symptoms was 1.0 years (1 day-16.4 years); median age at diagnosis was 1.9 years ( 1 day-17.1 years). There were 66 type I (73\%), two type II (2\%), no type III, 17 type IVa (19\%) and one type IVb (1\%) according to the Todani classification [18]. In five patients (5\%), the Todani classification could not be retrieved. There were 27 males $(30 \%)$ and 64 females $(70 \%)$, leading to a male-female ratio of $1: 2,4$. Comorbidity was present in three patients and consisted of Li-Fraumeni P53 mutation, congenital disorder of the glycosylation type Ia and galactosemia.

\section{Surgery}

Surgical parameters are depicted in Table 1. All patients underwent resection of the extrahepatic biliary tree with Roux-en-Y hepaticojejunostomy. Parenchyma resection during primary surgery was not performed. Seventy-nine patients $(87 \%)$ were operated via laparotomy and 12 patients (13\%) via laparoscopy. In one patient, laparoscopy was converted to laparotomy. Hospital stay was significantly shorter after laparoscopic resection ( 5 vs 9 days, $p=0.02)$ and in patients $>1$ year ( 8 vs 12 days, $p<0.01$ ). Operative time was significantly shorter in patients treated via laparotomy ( 3.5 vs $5.5 \mathrm{~h}, p=0.02$ ).

\section{Postoperative course}

Short-term complications occurred in 20 patients (22\%). Eight patients $(9 \%)$ required reoperation and/or ICU admittance for short-term complications. One patient died within 30 days postoperatively due to an abdominal compartment syndrome in combination with congenital disorder of the glycosylation type Ia. Therefore, analysis of long-term complications was performed in 90/91 patients.

Median follow-up was 13.6 years $(0.8-26.0)$. Long-term complications occurred in 16 patients $(16 / 90,17 \%)$. Eight patients $(8 / 90,9 \%)$ required reoperation or radiological intervention. One patient $(1 / 90,1 \%)$ died $>30$ days postoperatively because of non-related disease.

\section{Risk factors for postoperative complications}

\section{Surgical technique}

Tables 2 and 3 depict short-term ( $<30$ days) and long-term ( $>0$ days) postoperative complications, respectively. Two patients $(2 / 12,18 \%)$ developed short-term complications after laparoscopic surgery versus 18 patients $(18 / 79,24 \%)$ after laparotomy $(p=0.5)$. Five patients $(5 / 12,42 \%)$ developed long-term complications after laparoscopic surgery versus 11 patients $(11 / 78,14 \%)$ after laparotomy $(p=0.04)$. The majority of long-term complications occurred within 2 years after surgery $(65 \%)$. Complications consisted mainly of cholangitis $(n=12)$ and anastomotic strictures $(n=4)$.

\section{Age at the time of surgical intervention}

As shown in Tables 2 and 3, 10 patients (10/30, 33\%) who underwent surgery before 1 year of age developed short-

Table 1 Surgical parameters in patients undergoing surgery for choledochal malformation in the Netherlands between January 1, 1989 and December 31, 2014

\begin{tabular}{lccccc}
\hline & All $(n=91)$ & $\begin{array}{l}\text { Laparoscopy } \\
(n=12)\end{array}$ & Laparotomy $(n=79)$ & $\begin{array}{l}\text { Surgery }<1 \text { year of age } \\
(n=30)\end{array}$ & $\begin{array}{l}\text { Surgery }>1 \text { year of age } \\
(n=61)\end{array}$ \\
\hline $\begin{array}{l}\text { Median age at surgery } \\
\text { (years) }\end{array}$ & $2.1(0.03-17.7)$ & $1.1(0.03-8.9)$ & $2.3(0.06-17.7)(0.2)$ & $0.2(0.03-1.0)$ & $4.3(1.1-17.7)$ \\
$\begin{array}{l}\text { Median weight at } \\
\text { surgery (kg) }\end{array}$ & $\begin{array}{c}10.6(2.8-52.5) \\
(n=66)\end{array}$ & $\begin{array}{c}9.0(2.8-28) \\
(n=11)\end{array}$ & $\begin{array}{c}11.0(3.7-52.5)(n=55) \\
(p=0.3)\end{array}$ & $5.2(2.8-12)(n=24)$ & $15.8(9-52.5)(n=42)$ \\
$\begin{array}{l}\text { Median operative time } \\
\text { (hrs) }\end{array}$ & $\begin{array}{c}3.5(1.2-9.3) \\
(n=81)\end{array}$ & $\begin{array}{c}5.5(2.0-7.2) \\
(n=11)\end{array}$ & $\begin{array}{c}3.5(1.2-9.3)(n=70) \\
(p=0.03)\end{array}$ & $3.5(1.5-6.3)(n=27)$ & $3.5(1.7-9.3)(n=54)$ \\
$\begin{array}{l}\text { Median hospital stay } \\
\text { (days) }\end{array}$ & $9(2-61)(n=88)$ & $5(4-16)$ & $\begin{array}{c}(2-61)(n=76) \\
(p=0.02)\end{array}$ & $12(4-61)(n=29)$ & $\begin{array}{c}(p)(2-29)(n=59) \\
(p<0.01)\end{array}$ \\
\hline
\end{tabular}

kg kilograms, hrs hours 
Table 2 Short-term complications in patients after resection of choledochal malformation

\begin{tabular}{|c|c|c|c|c|c|}
\hline & $\begin{array}{l}\text { All } \\
(n=91)\end{array}$ & $\begin{array}{l}\text { Laparoscopy } \\
(n=12)\end{array}$ & $\begin{array}{l}\text { Laparotomy } \\
(n=79)\end{array}$ & $\begin{array}{l}\text { Surgery }<1 \text { year of } \\
\text { age }(n=30)\end{array}$ & $\begin{array}{l}\text { Surgery }>1 \text { year of } \\
\text { age }(n=61)\end{array}$ \\
\hline Total number of patients & 20 & $2(17 \%)$ & $\begin{array}{l}18(23 \%) \\
\quad(p=1.0)\end{array}$ & $10(33 \%)$ & $10(16 \%)(p=0.1)$ \\
\hline \multicolumn{6}{|l|}{ CD I } \\
\hline Total number of patients & $4(4 \%)$ & $0(0 \%)$ & $4(5 \%)$ & $3(10 \%)$ & $1(2 \%)$ \\
\hline Anuria & 1 & 0 & 1 & 1 & 0 \\
\hline Unexplained fever & 1 & 0 & 1 & 1 & 0 \\
\hline Ascites & 1 & 0 & 1 & 1 & 0 \\
\hline Pancreatitis & 1 & 0 & 1 & 0 & 1 \\
\hline \multicolumn{6}{|l|}{ CD II } \\
\hline Total number of patients & $8(9 \%)$ & $1(8 \%)$ & $7(9 \%)$ & $4(13 \%)$ & $4(7 \%)$ \\
\hline Unexplained fever & 1 & 0 & 1 & 1 & 0 \\
\hline Cholangitis & 3 & 1 & 2 & 3 & 0 \\
\hline Impetigo & 1 & 0 & 1 & 0 & 1 \\
\hline Skin infection & 2 & 0 & 2 & 0 & 2 \\
\hline Bile leakage & 1 & 0 & 1 & 0 & 1 \\
\hline \multicolumn{6}{|l|}{ CD III } \\
\hline Total number of patients & $6(8 \%)$ & $1(8 \%)$ & $5(6 \%)$ & $2(7 \%)$ & $4(7 \%)$ \\
\hline Bile leakage & 4 & 0 & 4 & 1 & 3 \\
\hline Deep infection & 2 & 0 & 2 & 0 & 2 \\
\hline Pleural fluid & 1 & 0 & 1 & 0 & 1 \\
\hline Ileus & 1 & 0 & 1 & 0 & 1 \\
\hline Duodenum perforation & 1 & 1 & 0 & 1 & 0 \\
\hline \multicolumn{6}{|l|}{ CD IV } \\
\hline Total number of patients & $1(1 \%)$ & 0 & $1(1 \%)$ & $1(3 \%)$ & $0(0 \%)$ \\
\hline Bile leakage & 1 & 0 & 1 & 1 & 0 \\
\hline Liver abscesses & 1 & 0 & 1 & 1 & 0 \\
\hline \multicolumn{6}{|l|}{ CD V } \\
\hline Total number of patients & $1(1 \%)$ & 0 & $1(1 \%)$ & 0 & $1(2 \%)$ \\
\hline $\begin{array}{l}\text { Abdominal compartment syndrome with } \\
\text { CDG type Ia comorbidity }\end{array}$ & 1 & 0 & 1 & 0 & 1 \\
\hline
\end{tabular}

This table describes the total number of complications that occurred and type of complications; some patients encountered more than one shortterm complications

$C D$ Clavien-Dindo, $C D G$ congenital disorder of the glycosylation

term complications versus 10 patients $(10 / 61,18 \%)$ who underwent surgery after 1 year of age $(p=0.2)$. There were significantly more long-term complications in patients operated before 1 year of age (12/30, 39\%) when compared with patients operated after 1 year of age $(4 / 60$, $8 \%, p<0.01)$.

Complication-free survival in relation to type of surgery and age at surgery

Median complication-free survival was 1.6 years (0.2-8.7 years) after laparoscopic surgery and 13.8 years $(0.1-25.9$ years $)$ after laparotomy $(p<0.01)$. There was no difference in median complication-free survival between patients undergoing surgery before 1 year of age and patients undergoing surgery after 1 year of age.

\section{Risk factors for postoperative short- and long-term complications}

To identify risk factors for short- and long-term complications, several patient and surgery-related parameters were tested (Table 4). There were no significant risk factors for the occurrence of short-term postoperative complications. However, complications were more prevalent in patients operated before 1 year of age than in patients 
Table 3 Long-term complications in patients after resection of choledochal malformation

\begin{tabular}{|c|c|c|c|c|c|}
\hline & $\begin{array}{l}\text { All } \\
(n=90)\end{array}$ & $\begin{array}{l}\text { Laparoscopy } \\
(n=12)\end{array}$ & $\begin{array}{l}\text { Laparotomy } \\
(n=78)\end{array}$ & $\begin{array}{l}\text { Surgical } \\
\text { intervention }<1 \text { year } \\
\text { of age }(n=30)\end{array}$ & $\begin{array}{l}\text { Surgical } \\
\text { intervention }>1 \text { year } \\
\text { of age }(n=60)\end{array}$ \\
\hline Total & $16(18 \%)$ & $5(42 \%)$ & $\begin{array}{l}11(14 \%) \\
\quad(p=0.03)\end{array}$ & $12(40 \%)$ & $4(7 \%)(p<0.01)$ \\
\hline Cholangitis & $12(13 \%)$ & $4(33 \%)$ & $8(10 \%)$ & $9(30 \%)$ & $3(5 \%)$ \\
\hline Stricture & $4(4 \%)$ & $2(17 \%)$ & $2(3 \%)$ & $3(10 \%)$ & $1(2 \%)$ \\
\hline Cirrhosis & $1(1 \%)$ & 0 & $1(1 \%)$ & $1(3 \%)$ & 0 \\
\hline Mechanical ileus & $1(1 \%)$ & 0 & $1(1 \%)$ & $1(3 \%)$ & 0 \\
\hline Gallstones & $2(2 \%)$ & 0 & $2(3 \%)$ & $1(3 \%)$ & $1(2 \%)$ \\
\hline Abscesses & $2(2 \%)$ & 0 & $1(1 \%)$ & $1(3 \%)$ & $0(0 \%)$ \\
\hline Portal hypertension & $2(2 \%)$ & 0 & $2(3 \%)$ & $2(7 \%)$ & $0(0 \%)$ \\
\hline Incisional hernia & $1(1 \%)$ & 0 & $1(1 \%)$ & 0 & $1(2 \%)$ \\
\hline Secondary parenchyma resection & $1(1 \%)$ & 0 & $1(1 \%)$ & $1(3 \%)$ & 0 \\
\hline Incomplete $\mathrm{CM}$ resection & $1(1 \%)$ & $1(8 \%)$ & 0 & 0 & $1(2 \%)$ \\
\hline $\begin{array}{l}\text { Complications requiring radiological } \\
\text { intervention or re-surgery }\end{array}$ & $8(9 \%)$ & $3(25 \%)$ & $\begin{array}{l}5(6 \%) \\
\quad(p=0.07)\end{array}$ & $6(20 \%)$ & $2(3 \%)(p=0.02)$ \\
\hline
\end{tabular}

This table describes the total number of complications that occurred and type of complications; some patients encountered more than one longterm complications

$C M$ choledochal malformation

Table 4 Risk factors for short- and long-term complications (univariately)

\begin{tabular}{lll}
\hline & $\begin{array}{l}\text { Odds } \\
\text { ratio }\end{array}$ & $\begin{array}{l}95 \% \text { confidence } \\
\text { interval }\end{array}$ \\
\hline $\begin{array}{l}\text { Short-term complications } \\
\text { Surgery }<1 \text { year of age }\end{array}$ & 2.5 & $0.8-7.1$ \\
$\begin{array}{l}\text { Long-term complications } \\
\text { Surgery }<1 \text { year of age }\end{array}$ & 9.3 & $2.7-32.5$ \\
$\begin{array}{l}\text { Laparoscopic technique } \\
\text { Occurrence of a short-term } \\
\text { complication }\end{array}$ & 4.4 & $1.2-16.2$ \\
\hline
\end{tabular}

operated at an older age (after 2 years). Surgical intervention before 1 year of age and laparoscopic resection were associated with a significantly higher risk for longterm complications (OR 4.4 and 9.3, respectively).

\section{Discussion}

In the present series we describe results from the first nationwide database from a Western country; consisting of 91 patients younger than 18 years who underwent surgery for choledochal malformation in the Netherlands. The incidence of CM was much higher than expected. Postsurgical morbidity was significant, about half of the patients who developed a complication needed radiological, endoscopical or surgical re-intervention. In univariate analysis, surgery within the first year of life and laparoscopic approach were associated with long-term complications. A multivariate analysis is necessary to investigate whether both age at surgery and laparoscopic resection are independently associated with a higher incidence in complications. The low incidence of the condition prevented multivariate analyses, despite the national collection of data over a prolonged period.

We found a specimen-proven surgical incidence of 1:59,000 live births in the present series. This incidence is at least two to three times higher than expected $(1: 100-150,000)$ for non-Asian countries [1, 2]. The current incidence might even be an underestimation: We expect that the incidence will probably even be higher when a similar national registry for patients $>18$ years of age is established. We might also not have been able to identify all children, as children might have been operated in another country or not operated at all.

Short-term postoperative complications are poorly reported in the literature, but our present data seem similar to the available data with a substantial overall rate of $22 \%$ [9, 21-23]. The long-term complication rate in the literature ranges between 5 and $15 \%$, and reoperation rates ranges between 1 and 20\% [9, 21-25]. Cholangitis occurs in $1-9 \%$ of the patients, stricture of the biliodigestive anastomosis occurs in 1-9\% of the patients, and there is a reoperation rate of $1-20 \%[9,21-25]$. We believe these numbers show a wide distribution mainly due to the 
variable length of follow-up [9, 21-25]. The present series demonstrates a relatively high overall long-term complication rate of $18 \%$. There seems a clear decrease in complication rate with an increase in age. Technically, surgery in older children is easier when compared to young children. This especially holds true for the biliodigestive anastomosis [11-13]. The difficulties in hepatobiliary surgery in young children have also been described in patients undergoing liver transplantation [26]. It is tempting to speculate that complication rates could therefore also be decreased by avoiding surgery in asymptomatic patients who have not reached 1 year of age. This might also be the case for anesthesiologic effects, which decrease sharply with age in children $[27,28]$. As surgery for CM in the asymptomatic patient can be considered prophylactic surgery, the risks of such major undertaking have to be weighed against the risks of watchful waiting. In asymptomatic patients, careful monitoring with regular ultrasound and laboratory checks until the child has reached 1 year of age (corresponding to ca. $10 \mathrm{~kg}$ ) should be able to early identify patients at a high risk for progressing to CMrelated complications which should therefore be operated early. This way, one should be able to prevent technically more demanding surgery after inflammation of the cyst. In the presence of CM-related complications, patients should be operated as soon as their clinical condition permits.

In the present series, $42 \%$ of the patients undergoing laparoscopic surgery suffered from a long-term complication. Children undergoing laparoscopic resection have a tendency to be younger than patients undergoing laparotomy ( 1.1 vs 2.3 years, $p=0.2$ ). This may have influenced the results, as surgery in younger children is associated with a higher incidence of complications in our series. Moreover, there can be a significant selection bias because the patients had not been randomized for laparoscopic or open surgery. These data suggest that we still might be in our learning curve. Laparoscopic (hepatobiliary) pediatric surgery has a long learning curve, especially in young children [29-31]. From the results of this study, no definitive conclusions can therefore be drawn regarding the laparoscopic approach of CM. While we do not advocate the avoidance of laparoscopic resection, we do argue for centralization of these procedures to increase numbers and thereby shorten the learning curve. Davenport et al. [32] demonstrated that centralization of care led to improvement of the outcomes of biliary atresia, another rare pediatric hepatobiliary disease. Centralization of care for children with CM may also lead to better outcomes.

A potential long-term consequence of $\mathrm{CM}$ is the development of a malignancy. We did not observe any malignancies during follow-up, but we do realize that our cohort is still relatively young. In order to detect malignancies in the Western CM patients, a longer follow-up has to be established. Lifelong follow-up therefore remains important. Several other studies investigated the malignancy risk after excision of a CM [22, 29, 33, 34]. The malignancy risk is considered to increase with age at surgery, and the cumulative biliary malignancy risk 25 years after primary surgery has been reported to be as high as $11 \%$ [30]. These data stem from the high volume Asian centers and could be different in patients in Western countries. In a recent large cohort, Soares et al. [22] mentioned the development of malignancy in $0.7 \%$ in Western patients. However, with a median follow-up of 2.7 years in their pediatric cohort and 11 years in our cohort (with no malignancies), the malignancy risk of Western CM patients operated at infancy seems low.

Theoretically, the retrospective nature of our study could have underestimated the incidence of postoperative complications. In the Netherlands, treatment of CM is only performed in one of the six pediatric surgical centers. Therefore, most (if not all) postoperative complications are expected to be registered in the patients' files. The $\mathrm{NeSCHoC}$ is the first nationwide database on choledochal malformations spanning several decades. This enabled us to thoroughly investigate a rare disease. This study is one of the first to fully describe the surgical outcomes in patients diagnosed and operated on $\mathrm{CM}<18$ years of age. The retrospective nature of the study has led to an unavoidable gap in data in several areas, not to mention the changes in care that have taken place over 25 years. However, we feel that it is a major step forward to address relevant issues of this rare condition. $\mathrm{NeSCHoC}$ is now converted into a prospective database. The present database still contains a relatively small cohort of patients precluding multivariate analysis and thereby further detailed analysis of risk factors. Such analyses should be done when larger numbers become available, for which international cooperation (for instance, via an online registry such as the Biliary Atresia and Related Disease (BARD) database) is desirable.

\section{Conclusion}

While CM remains a rare disease, the incidence of $\mathrm{CM}$ in the Netherlands is much higher than expected. Surgery for CM carries significant short-term and long-term morbidity warranting a lifelong follow-up. In the present series, a younger age at surgery and laparoscopic surgery were associated with a higher risk of complications. These findings suggest that postponing surgery in asymptomatic children can decrease complication rates. Since laparoscopic surgery was often performed in the younger age group, it is hard to determine whether age and laparoscopic surgery are independently associated with a higher number 
of complications. Laparoscopic hepatobiliary surgery in small children should only be performed by surgeons with a wide experience in laparoscopy and hepatobiliary surgery. We feel that in the Dutch situation this can only be reached via centralization of care of this rare disease.

\section{Compliance with ethical standards}

\section{Conflict of interest None.}

Open Access This article is distributed under the terms of the Creative Commons Attribution 4.0 International License (http://crea tivecommons.org/licenses/by/4.0/), which permits unrestricted use, distribution, and reproduction in any medium, provided you give appropriate credit to the original author(s) and the source, provide a link to the Creative Commons license, and indicate if changes were made.

\section{References}

1. Gigot JF, Nagorney DM, Farnell MB et al (1996) Bile duct cysts: a changing spectrum of presentation. J Hepatobiliary Pancreat Surg 3(4):405-411

2. Singham J, Yoshida EM, Scudamore CH (2009) Choledochal cysts: part 1 of 3: classification and pathogenesis. Can J Surg 52(5):434-440

3. O’Neill JA Jr (1992) Choledochal cyst. Curr Probl Surg 29(6):361-410

4. Singham J, Yoshida EM, Scudamore CH (2009) Choledochal cysts: part 2 of 3: diagnosis. Can J Surg 52(6):506-511

5. Yamaguchi M (1980) Congenital choledochal cyst. Am J Surg 140(5):653-657

6. Todani T, Urushihara N, Morotomi Y et al (1995) Characteristics of choledochal cysts in neonates and early infants. Eur J Pediatr Surg 5(3):143-145

7. Gardikis S, Antypas S, Kambouri K et al (2005) The Roux-en-Y procedure in congenital hepato-biliary disorders. Rom J Gastroenterol 14(2):135-140

8. Singham J, Yoshida EM, Scudamore CH (2010) Choledochal cysts. Part 3 of 3: management. Can J Surg 53(1):51-56

9. Urushihara N, Fukumoto K, Fukuzawa H et al (2012) Long-term outcomes after excision of choledochal cysts in a single institution: operative procedures and late complications. J Pediatr Surg 47(12):2169-2174

10. Todani T, Watanabe Y, Urushihara N et al (1995) Biliary complications after excisional procedure for choledochal cyst. J Pediatr Surg 30(3):478-481

11. Stringer MD, Dhawan A, Davenport M et al (1995) Choledochal cysts: lessons from a 20 year experience. Arch Dis Child 73(6):528-531

12. Lee S-C, Kim H-Y, Jung S-E et al (2006) Is excision of a choledochal cyst in the neonatal period necessary? J Pediatr Surg 41(12): 1984-1986

13. Suita S, Shono K, Kinugasa Y et al (1999) Influence of age on the presentation and outcome of choledochal cyst. J Pediatr Surg 34(12): $1765-1768$

14. van den Eijnden MHA, de Kleine RH, Verkade HJ et al (2014) Controversies in choledochal malformations: a survey among Dutch pediatric surgeons. Eur J Pediatr Surg 25(5):441-448

15. Urushihara N, Fukuzawa H, Fukumoto K et al (2011) Totally laparoscopic management of choledochal cyst: roux-en-Y
Jejunojejunostomy and wide hepaticojejunostomy with hilar ductoplasty. J Laparoendosc Adv Surg Tech A 21(4):361-366

16. Wang B, Feng Q, Mao J et al (2014) Early experience with laparoscopic excision of choledochal cyst in 41 children. J Pediatr Surg 47(12):2175-2178

17. Liem NT, Pham HD, Dung LA et al (2012) Early and intermediate outcomes of laparoscopic surgery for choledochal cysts with 400 patients. J Laparoendosc Adv Surg Tech A 22(6):599-603

18. Katabi N, Pillarisetty VG, DeMatteo R et al (2014) Choledochal cysts: a clinicopathologic study of 36 cases with emphasis on the morphologic and the immunohistochemical features of premalignant and malignant alterations. Hum Pathol 45(10):2107-2114

19. Voyles CR, Smadja C, Shands WC et al (1983) Carcinoma in choledochal cysts. Age-related incidence. Arch Surg 118(8): 986-988

20. Ishibashi T, Kasahara K, Yasuda Y et al (1997) Malignant change in the biliary tract after excision of choledochal cyst. Br J Surg 84(12):1687-1691

21. Todani T, Watanabe Y, Toki A et al (2013) Classification of congenital biliary cystic disease: special reference to type Ic and IVA cysts with primary ductal stricture. J Hepatobiliary Pancreat Surg 10(5):340-344

22. Clavien PA, Barkun J, de Oliveira ML et al (2009) The ClavienDindo classification of surgical complications: five-year experience. Ann Surg 250(2):187-196

23. CBS StatLine, http://statline.cbs.nl/Statweb/. Accessed September 2015

24. Ohtsuka H, Fukase K, Yoshida H et al (2013) Long-term outcomes after extrahepatic excision of congenital choladocal cysts: 30 years of experience at a single center. Hepatogastroenterology 62(137): $1-5$

25. Soares KC, Kim Y, Spolverato G et al (2015) Presentation and clinical outcomes of choledochal cysts in children and adults: a multi-institutional analysis. JAMA Surg 150(6):577-584

26. Saing H, Han H, Chan KL et al (1997) Early and late results of excision of choledochal cysts. J Pediatr Surg 32(11):1563-1566

27. Narayanan SK, Chen Y, Narasimhan KL et al (2013) Hepaticoduodenostomy versus hepaticojejunostomy after resection of choledochal cyst: a systematic review and meta-analysis. J Pediatr Surg 48(11):2336-2342

28. Murr MM, Gigot JF, Nagorney DM et al (1999) Long-term results of biliary reconstruction after laparoscopic bile duct injuries. Arch Surg 134(6):604-610

29. Shen H-J, Xu M, Zhu H-Y et al (2015) Laparoscopic versus open surgery in children with choledochal cysts: a meta-analysis. Pediatr Surg Int 31(6):529-534

30. Zhen C, Xia Z, Long L et al (2015) Laparoscopic excision versus open excision for the treatment of choledochal cysts: a systematic review and meta-analysis. Int Surg 100(1):115-122

31. Speicher PJ, Nussbaum DP, White RR et al (2014) Defining the learning curve for team-based laparoscopic pancreaticoduodenectomy. Ann Surg Oncol 21(12):4014-4019

32. Davenport M, Ong E, Sharif K et al (2011) Biliary atresia in England and Wales: results of centralization and new benchmark. J Pediatr Surg 46(9):1689-1694

33. Wen Z, Liang H, Liang $\mathbf{J}$ et al (2017) Evaluation of the learning curve of laparoscopic choledochal cyst excision and Roux-en-Y hepaticojejunostomy in children: CUSUM analysis of a single surgeons' experience. Surg Endosc 31(2):778-787

34. Oomen MWN, Hoekstra LT, Bakx R et al (2010) Learning curves for pediatric laparoscopy: how many operations are enough? The Amsterdam experience with laparoscopic pyloromyotomy. Surg Endosc 24(8):1829-1833 